\title{
An Analysis of the Effect of a Cyber Home Learning System on Korean Secondary School Students' English Language Achievement and Attitude
}

\section{Ji Hye Shin \& Peggy Albers}

This study examined the effectiveness of a Cyber Home Learning System (CHLS), an online learning system currently being employed in South Korea to improve the access and quality of public education as well as to reduce private tutoring expenditures. The quasi-experimental research design used experiment and survey methods to learn about the impact of CHLS on student performance and to ascertain students' perceptions of the system. The results of the experiment indicated that no statistically significant differences in test performance existed between the experimental and control groups. This finding suggested that CHLS did not have an impact on student performance overall. However, after the data were disaggregated according to ability level, students in the advanced level showed statistically significant differences between the experimental and control groups. Results from the survey indicated that the CHLS was particularly effective for those who are motivated to voluntarily participate in academic activities and who have the capability for self-initiated study. The CHLS can be considered a useful supplement but not a replacement for secondary private tutoring. To better address the needs of other learners, the English content of CHLS may need to be further modified to match students' varying proficiency levels and learning styles.

Cette étude a porté sur l'efficacité d'un système d'apprentissage en ligne, Cyber Home Learning System - CHLS, actuellement employé en Corée du Sud pour améliorer la qualité de l'éducation publique, en augmenter l'accessibilité, et réduire les frais liés aux services de tutorat privé. Le plan de recherche quasi-expérimental s'est appuyé sur l'expérimentation et des méthodes d'enquête pour en apprendre sur l'impact du CHLS sur le rendement des élèves et pour confirmer les perceptions qu'ont les élèves du système. Les résultats de l'expérience n'ont indiqué aucune différence statistiquement significative entre le groupe expérimental et le groupe témoin, ce qui portait à croire que le CHLS n'avait pas eu d'impact sur le rendement global des élèves. Une fois les données ventilées par niveau de compétence par contre, elles ont révélé des différences statistiquement significatives entre les élèves avancés du groupe expérimental et ceux du groupe témoin. Les résultats de l'enquête ont indiqué que le CHLS était particulièrement efficace chez les élèves motivés à participer aux activités académiques et capables d'apprendre de façon autonome. On peut considérer le CHLS un complément 
utile à l'apprentissage, mais pas une solution de remplacement aux services de tutorat privé. Afin de mieux répondre aux besoins des autres apprenants, il se peut que le contenu en anglais du CHLS doive être modifié davantage de sorte à refléter les niveaux de compétence et les styles d'apprentissage variés.

Internet use has become an everyday occurrence for a large part of the population in the world. At the tap of a return button, people access the Internet for finding information, getting directions, and studying courses on any topic online (McAuley, Stewart, Siemens, \& Cormier, 2010). With access to innumerable online resources, e-learning policies and initiatives over the past few years have begun to make possible the promise of the "self-directed" and "independent" e-learning (Beetham \& Sharpe, 2013), especially for students who also seek out self-directed learning.

South Korea currently faces a number of pressing educational issues such as increased household private tutoring expenses, deteriorating quality of public education, and fierce competition surrounding the Korean Scholastic Aptitude Test (KSAT; Park, 2009). These challenges often result in parents' disillusionment with the educational system, as well as a decline in teacher self-image. The dissatisfaction of students and parents with public education has in recent years led to extreme dependence on incredibly expensive private after-school education to compensate for the perceived deficiencies of public education (Hwang, Yang, \& Kim, 2010). This trend toward increased reliance on private tutoring reveals a growing gap in access to educational opportunities that jeopardizes the egalitarian ideals of Korean society.

In order to address these education-related challenges and respond to the exploding computer literacy demands accompanying the rapid technological development of Korean society, policy makers have begun to make substantial reforms to the Korean educational system. Information communication technology (ICT) use in education and e-learning has been identified as a key means by which to meet computer literacy needs as well as to expand educational opportunity and improve satisfaction with public education in Korea.

This article addresses the significant role that one self-learning program in South Korea plays in English as a Foreign Language (EFL) students' learning to position them for better chances to get into their first-choice universities. The purpose of this quasi-experimental study was to examine the effectiveness of the Cyber Home Learning System (CHLS) as a supplementary instructional aid, and to elicit participants' perceptions of the CHLS in terms of its advantages and limitations. Three research questions guided the study: (a) Does CHLS improve EFL learners' level of English proficiency? (b) Which level of EFL learners among lower, intermediate, and advanced benefits from using CHLS? (c) Do EFL learners perceive CHLS as effective and helpful English-language learning tools? 


\section{Computer-Assisted Language Learning and E-Learning}

Research comparing distance education to traditional face-to-face instruction indicates that studying at a distance can be as effective as traditional instruction for supporting self-study, especially when instructional methods and technologies used are appropriate to the instructional aims, studentto-student interaction, and timely feedback (Bernard et al., 2004; Sitzmann, Kraiger, Stewart, \& Wisher, 2006; Verduin \& Clark, 1991). Further, online access to programs removes learning from the physical boundaries of schools and into spaces where students can work with materials on their own time and with lessons prepared by experts. The Korean Ministry of Education, Science and Technology and Korea Education and Research Information Service (MEST \& KERIS, 2012) argues that online access to learning supports students' rights to equitable education by enabling students from all geographic areas, those with physical disabilities, or those who have not passed required courses to study and learn at their own pace and on their own time (MEST \& KERIS, 2012).

Although language learning through Internet access and computer technology predominantly arose as a phenomenon in the mid 1990s, investigations on the capabilities of technology for language instruction started in the 1960s by teachers and researchers at universities (Chapelle, 2005). Between the 1960s and 1980s, researchers in this area studied questions of whether computer-assisted instruction was better for language learning than classroom instruction. Further, these researchers attempted to measure the acquisition rate and mastery of grammar and vocabulary taught in a computer-assisted language learning (CALL) environment as compared to a teacher-led classroom (Heift \& Chapelle, 2012).

Research into the effectiveness of CALL is mixed. A number of studies reported a significant difference in achievement for CALL users over nonusers in learning English as a foreign language (Almekhlafi, 2006; Jung, 2005; Triantafillou, Pomportsis, \& Demetriadis, 2003). They found that a wide array of information technology options exists in language education, and each media has its own set of advantages and constraints. Affordances identified in the research literature for use of online learning software include access to an endless variety of materials, greater choice, authenticity, and communication with ESL/EFL learners (Kanuka, 2008). Online learning offers access to an enormous and diverse collection of raw data that learners must organize and comprehend to attain their learning objectives. The benefit of access to these materials is that it forces educators to give learners greater autonomy (Beetham \& Sharpe, 2013, p. xvii). A second affordance of online learning is freedom of choice (Bouhnik \& Marcus, 2006). The Internet encourages students to actively engage in their learning and gives them a substantial degree of choice of what to study, where to study, how to study, and with whom (Chodorow, 1996; Rosenberg, 2001; Wentling et al., 2000). 
Third, online learning can create simulated learning environments that provide learners with experiences that closely match authentic situations. To fully take advantage of the potential authenticity of online learning, Herrington, Reeves, and Oliver (2010) insisted that online learning courses need to provide tasks that have real-world relevance and a sustained period of time for investigation, and can be integrated across subject areas.

As promising as online language learning may be, it also comes with extensive cost, effort, and time to develop infrastructures and software necessary to ensure its smooth operation (Jang, 2006). A challenge relates to the guidance required for learners to use the system to best advantage. The interactive nature of online learning allows learners to explore a variety of resources and establish connections with other knowledge domains that are meaningful to them (Woo \& Reeves, 2007). However, meaningful interactions are unlikely to occur without the provision of an instructional design model that fosters the efficient pursuit of these resources and the productive forging of these connections. At present, the real threat of information overload exists, given that online learning might cause the learners distraction (Jang, 2003).

A number of countries have introduced and developed e-learning as a means to support student self-study. In Canada, K-12 online learning has continued to develop slowly; however, there has been little dissemination outside of Canada and between individual provinces (Barbour \& Stewart, 2008). In other words, there is no uniform way in which e-learning happens or is organized (Murphy, Rodríguez-Manzanares, \& Barbour, 2011). According to State of the Nation: K-12 Online Learning in Canada (Barbour, 2012), there are five $\mathrm{K}-12$ distance education programs that fall under provincial jurisdiction (two in Ontario, and one each in Manitoba, Alberta, and Saskatchewan). Other First Nations, Metis, and Inuit organizations have also been exploring the adoption of $\mathrm{K}-12$ distance education. However, for various reasons-lack of bandwidth or connectivity, lack of community buy-in, lack of expertise for implementation, and others-they have not yet established distance education programs (Barbour, 2012). In their meta-analysis of online learning, Bernard et al. (2004) found that asynchronous learning environments had more positive effects in terms of achievement and attitudes than synchronous; however, retention rates were better for synchronous. In general, these researchers found that asynchronous environments provided more flexibility and less chance of lecture-based instruction as was often the case in synchronous learning. Although the design of the course was critical to how well students achieved, with younger students often benefitting more from synchronous than asynchronous environments, Bernard et al. concluded that the synchronous learning environment represented a poorer quality replication of classroom instruction. 


\section{Rationale for Study}

According to Woo and Reeves (2007), the online learning process needs to be carefully analyzed and understood to increase meaningful interactions and ensure efficient information search and retrieval in these environments. In our search of the literature, we found that little has been done specifically on systems asynchronously designed to support language learning, especially as it concerns constraints on wider content access and accommodating learner preferences. That is, online language learning systems are sometimes less interactive than planned and fail to provide learners with sufficient content access or an ability to select their preferred content presentation format. In an interactive online language learning environment, the capability to provide wide access to learning materials and learner-driven selection of content presentation format is critical for encouraging student engagement and learning effectiveness, so these limitations must be urgently addressed (Zhang, 2005).

\section{Cyber Home Learning System}

The CHLS is a national open-access customized state-of-the-art learning system implemented in South Korea in 2004 that enables all K-12 learners with web access to study a range of topics, including the English language. Currently, 4.4 million students participate in the CHLS voluntarily or obligatorily by school curriculum; however, the daily log-in of 156,000 (as of 2009) does not reflect total enrollment (MEST \& KERIS, 2012). The CHLS was created with three objectives in mind: (a) to close the educational access divide, (b) to reduce private tutoring expenses, and (c) to improve the quality of public education. An important feature of CHLS is that it provides student users with individualized study management services. These services include customized learning using content for self-motivated study, a Q \& A page with direct access to cyber teachers, formative and summative assessment of academic performance through online assessment tools, and a career counselling service for college applications (Cho, Kim, Bae, \& Choi, 2009). Since the launch of CHLS, efforts have been made to gradually expand the service to all schools and grades. In 2007, customized content was developed for primary school Grades 4-6, middle school, and high school Grade 10. In 2012, local school districts conducted a trial campaign called the "Saturday Mentoring Service." Curricula were revised based on this trial campaign, and the content management and distribution system was expanded to more cities and provinces (MEST \& KERIS, 2012).

However, investigations of CHLS reveal that students were unsatisfied with their ability to concentrate on it. Study findings showed that only approximately $50 \%$ of the respondents indicated they were satisfied with their learning with CHLS (Kwon et al., 2006; Lee \& Lee, 2005), and students reported negative perceptions in strictly online learning environments with 
no face-to-face component (Adam \& Nel, 2009). Most of the studies of CHLS focused on a range of common subjects (e.g., social studies, science, mathematics, Korean literature); thus, little is known about how CHLS impacts students' English language learning, and whether they perceive CHLS as helpful in their learning of English. Because the English language is becoming increasingly important in the minds of South Korean parents, and English as a foreign language (EFL) is becoming more important for success in children's education (Lee \& Koo, 2006), this study set out to investigate how CHLS informed the language learning in two Korean Grade 9 EFL classrooms.

It is hoped that this study will offer insights into understanding how selfdirected study within online programs may be a useful tool for students and teachers alike to support the language and technology demands required for success in a highly wired world.

\section{Methodology}

\section{Participants}

Participants in the study were 147 Grade 9 middle school students (77 male, 70 female) in Seoul, South Korea. Prior to beginning the experiment, a brief questionnaire was administered to ascertain the participants' personal Internet usage and online English learning experiences. According to the survey results, more than $90 \%$ of the study participants owned computers, and those who did not own computers at home had access to computers in public libraries or the computer lab at school. All the participants had had substantial computer-based learning experiences as part of the regular curriculum since elementary school.

\section{Description of all the instruments}

The CHLS provides two types of learning service: a classroom option and a self-study option. The classroom option is the service model that provides individualized learning management by a cyber teacher. The cyber teacher continuously manages the students' progress and assignments. Upon completion of the course, students are issued a certificate of completion by CHLS that reports their progress in terms of assignment and assessment scores. The self-study option occurs when students study without any assistance from cyber teachers. Students select learning content according to their own preference. In this study, the self-study option was used in the experimental condition. The CHLS self-study option for Grade 9 students consisted of 12 units, with 9 lessons in each, and included a variety of learning task types. This approach allowed students to construct how they worked within CHLS.

Figure 1 is a screenshot of the CHLS system with a focus on performance of learning tasks as the primary type of learning activity. In comparison to 
other problem-solving activities, these tasks have the advantage that learners are able to self-assess their work throughout the problem-solving process ( $\mathrm{Su}$, Bonk, Magjuka, Liu, \& Lee, 2005). The learning content for each unit consists of Motivation, Learning Instructions, Task 1, Task 2, Task 3, and Wrap-up. After performing each task, students are encouraged to work through supplementary or advanced tasks.

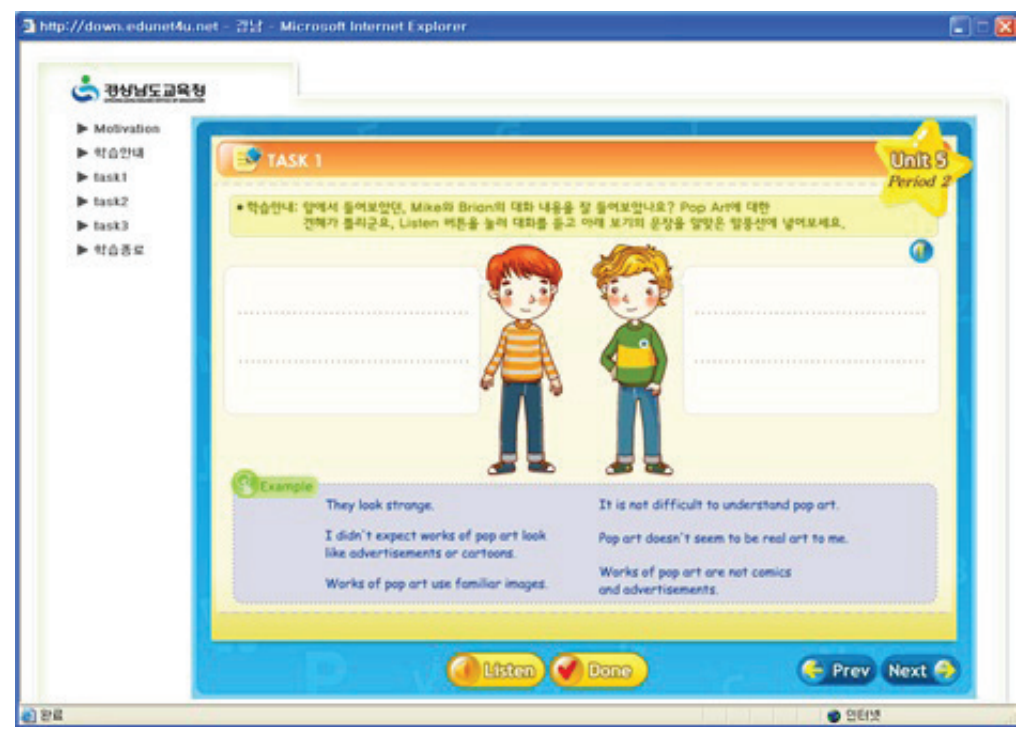

Figure 1. Overview of the Cyber Home Learning System English lesson.

Figure 2 is a screenshot of the "Need Help" and "Challenge" sections of the site. Clicking on the "Need Help" button provides assistance for students who struggle with the content material, while the "Challenge" button leads students to advanced language enrichment.

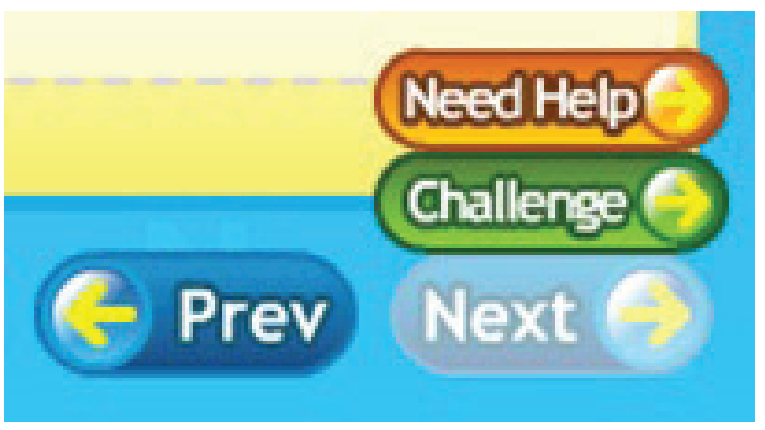

Figure 2. Screenshot of "Need Help" and "Challenge" buttons. 
Figure 3 is a screenshot showing an example of a unit of study in CHLS. Note that the units in CHLS do not include any pre-assessments because the main activities in the tasks already incorporate diagnostic components. Formal assessments are administered only at the end of each unit. Throughout the four-week experimental phase, subjects in the experimental group were encouraged to self-study for at least one task every day.

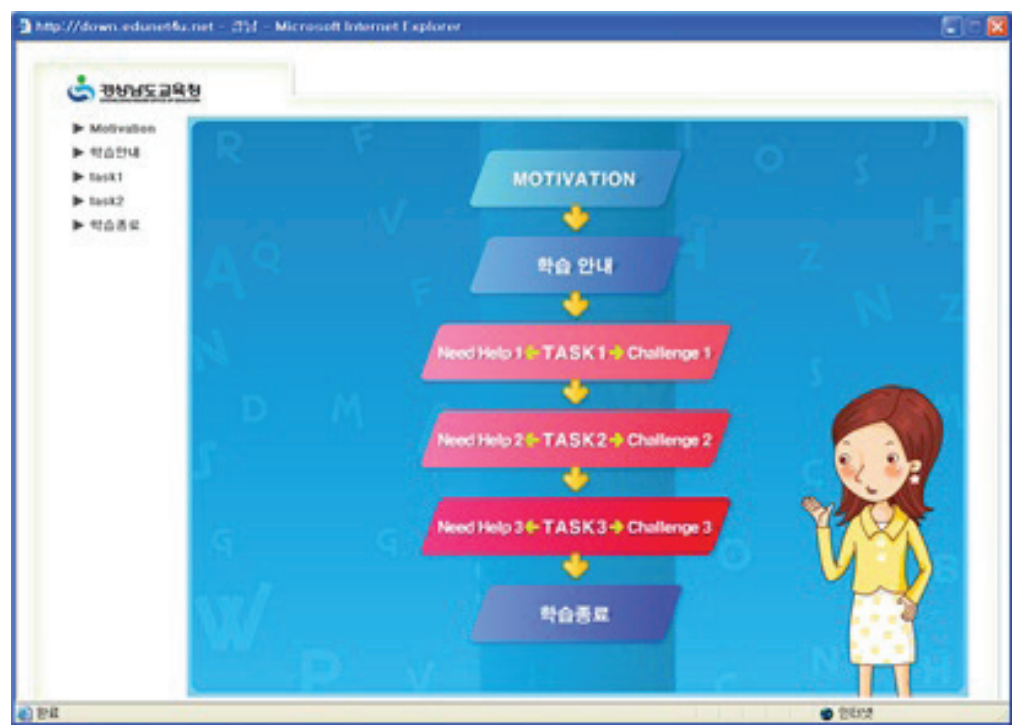

Figure 3. Screenshot of a sample CHLS English task.

\section{Research design}

The study used a quasi-experimental design and occurred over one month during the regular academic year. During the first week of the study period, the experimental group received English language instruction in their regular classroom setting incorporating the CHLS system. The control group received their regular English instruction without access to the CHLS system. Beginning in the second week, the experimental group was assigned to selfstudy using CHLS at home in addition to their regular classroom instruction. The control group received their regular classroom instruction. To maintain the experimental group's participation, subjects in the experimental group received credits for demonstrating regular CHLS activity through frequent login times.

Before the experiment, all participating students completed the researcherdesigned questionnaire that asked about their learning environment, Internet usage, Internet English learning experiences, and private tutoring experience. Chapters 1 and 2 were taught before the pretest, and Chapter 3 was taught 
between pretest and posttest. On the first day of the experiment, a pretest was administered to test all participants' English proficiency and to determine equivalence of the group. This occurred in the second month of the academic year (April) and consisted of 25 multiple-choice questions -6 listening, 12 multiple-choice reading, and 7 writing items $(\alpha=.82)$-based on Chapters 1 and 2 of the textbook used by the teacher. After one month of using CHLS, a posttest on the material in Chapter 3 of the class textbook was administered to both groups in May to determine any shift in English proficiency. The test scores were scaled between 0 and 100. A survey was administered to the experimental group at the end of May to determine perceptions of learning through the CHLS. This researcher-designed survey consisted of five multiple-choice questions and one open-ended question. The survey assessed participants' perceptions of CHLS, level of interest in the learning activities, perceptions of the difficulty level of the activities, and their willingness to continue CHLS to supplement their English language education.

\section{Analysis procedure}

Mean and standard deviations were calculated and $t$-tests were performed on pretest scores to identify any possible differences between the experimental group and control group at the outset of the study. After the experiment, mean and standard deviations were calculated and a $t$-test was performed to compare the experimental and control group to discover if the results revealed meaningful differences between the two groups. The experimental group and the control group were randomly selected among eight classes taught by the same teacher; both received similar types of instruction based on the school curriculum. The groups were each divided into three subgroups-lower, intermediate, and advanced-representing various ability levels according to their pretest results. A post-experiment $t$-test was performed for the same level subgroups to look for significant differences.

\section{Results}

\section{Analysis of CHLS effectiveness}

\section{Experimental group and control group pretest performance}

A pretest was administered at the outset of the experiment to establish participants' English proficiency levels for Experimental Group A (regular classroom instruction + CHLS) and Control Group B (regular classroom instruction only). A $t$-test was performed on pretest scores to see if the two groups were significantly different.

As shown in Table 1, the mean score of Experimental Group A was 67.1 $(S D=19.53)$ and the mean score of Control Group B was $66.7(S D=20.01)$. Thus, there was no significant difference between the experimental and control group in their pretest scores, $t(457)=.22, p=.83$. 
Table 1

Pretest Comparison Between Two Groups

\begin{tabular}{lrrrrrr}
\hline Group & $N$ & $M$ & $S D$ & $t$ & d.f. & $p$ \\
\hline Experimental Group A & 73 & 67.1 & 19.53 & .22 & 457 & .83 \\
Control Group B & 74 & 66.7 & 20.01 & & & \\
\hline
\end{tabular}

\section{Experimental group and control group posttest performance}

A $t$-test was also performed on posttest scores to identify any potential differences between Experimental Group A and Control Group B. The posttest consisted of 25 items: 6 listening, 15 multiple-choice reading, and 4 writing items $(\alpha=.84)$.

As shown in Table 2, the posttest mean for Experimental Group A was 59.1 $(S D=22.38)$ and the mean of Control Group B was $61.6(S D=20.76)$. There were no statistically significant differences in posttest scores between these two groups, $t(450)=-1.16, p=.25$. These results suggest practice with CHLS did not significantly improve participants' course performance.

Table 2

Posttest Comparison Between Two Groups

\begin{tabular}{lrrrrrr}
\hline Group & $N$ & $M$ & $S D$ & $t$ & d.f. & $p$ \\
\hline Experimental Group A & 73 & 59.1 & 22.38 & -1.16 & 450 & .25 \\
Control Group B & 74 & 61.6 & 20.76 & & & \\
\hline
\end{tabular}

Analysis of CHLS effectiveness for advanced, intermediate, and lower subgroups

Pretest and posttest results were disaggregated to allow for an analysis of advanced, intermediate, and lower subgroups to ascertain whether any CHLS learning effects existed that were dependent on participants' English proficiency level. Each experimental subgroup (A-1, A-2, and A-3) was then compared with its control counterpart (B-1, B-2, and B-3) at the same proficiency level.

Table 3 presents the analysis of the pretest results that revealed no statistically significant differences across any of the ability groupings. The advanced participants demonstrated no significant difference in test performance between Group A-1 $(M=81.4, S D=12.22)$ and Group B-1 $(M=81.1, S D=10.86)$, $t(160)=.20, p=.84$. The intermediate-level participants in Group A-2 $(M=$ $57.9, S D=12.74)$ and B-2 $(M=59.1, S D=11.63)$ also showed no significant difference in test scores, $t(156)=-.55, p=.58$. Likewise, the lower-level students in Group A-3 $(M=37.9, S D=12.90)$ revealed no significant difference from 
those in Group B-3 $(M=36.4, S D=11.63), t(139)=.70, p=.49$. These results suggest that all three groups were similar to each other at the beginning of the experiment.

Table 3

Analysis on the Pretest on Advanced, Intermediate, and Lower Groups

\begin{tabular}{|c|c|c|c|c|c|c|c|}
\hline Group & & $N$ & $M$ & $S D$ & $t$ & d.f. & $p$ \\
\hline \multirow{3}{*}{$\begin{array}{l}\text { Advanced } \\
\text { Level }\end{array}$} & Experimental Group A-1 & 25 & 81.4 & 12.22 & \multirow{3}{*}{.20} & \multirow{3}{*}{160} & \multirow{3}{*}{.84} \\
\hline & & & & & & & \\
\hline & Control Group B-1 & 25 & 81.1 & 10.86 & & & \\
\hline \multirow{2}{*}{$\begin{array}{l}\text { Intermediate } \\
\text { Level }\end{array}$} & Experimental Group A -2 & 24 & 57.9 & 12.74 & \multirow{2}{*}{-.55} & \multirow{2}{*}{156} & \multirow{2}{*}{.58} \\
\hline & Control Group B-2 & 25 & 59.1 & 11.63 & & & \\
\hline \multirow{2}{*}{$\begin{array}{l}\text { Lower } \\
\text { Level }\end{array}$} & Experimental Group A -3 & 24 & 37.9 & 12.90 & \multirow{2}{*}{.70} & \multirow{2}{*}{139} & \multirow{2}{*}{.49} \\
\hline & Control Group B-3 & 24 & 36.4 & 11.63 & & & \\
\hline
\end{tabular}

Table 4 presents the analysis of the posttest results that revealed there were no statistically significant differences in posttest scores across the intermediate and lower levels of the ability groupings. Participants in Group A-2 $(M=57.8, S D=13.66)$ and B-2 $(M=59.9, S D=11.27)$ showed no significant difference in test scores, $t(156)=-1.05, p=.30$. Likewise, the students in Group A-3 $(M=34.8, S D=11.14)$ revealed no significant difference from those in Group B-3 $(M=33.9, S D=10.66), t(139)=.46, p=.65$. However, the advanced

Table 4

Analysis on the Posttest on Advanced, Intermediate, and Lower Groups

\begin{tabular}{llrrrrrr}
\hline Group & & $N$ & $M$ & $S D$ & $t$ & d.f. & $p$ \\
\hline $\begin{array}{l}\text { Advanced } \\
\text { Level }\end{array}$ & Experimental Group A-1 & 25 & 83.4 & 10.46 & & & \\
& Control Group B-1 & 25 & 78.1 & 8.66 & & & \\
& Experimental Group A -2 & 24 & 57.8 & 13.66 & & & \\
$\begin{array}{l}\text { Intermediate } \\
\text { Level }\end{array}$ & Control Group B-2 & 25 & 59.9 & 11.27 & & & \\
& Experimental Group A -3 & 24 & 34.8 & 11.14 & & & \\
$\begin{array}{l}\text { Lower } \\
\text { Level }\end{array}$ & Control Group B-3 & 24 & 33.9 & 10.66 & & & \\
\hline
\end{tabular}

${ }^{*} p<0.05$ 
participants in Group A-1 $(M=83.4, S D=10.46)$ demonstrated significant difference in test performance from Group B-1 $(M=78.1, S D=8.66), t(160)=$ $.50, p=.04$. This result suggests that CHLS English content was effective only with advanced-level students.

\section{Surveys of student perceptions regarding CHLS}

A post-experiment survey with six items scored on a 5-point Likert scale was administered to the experimental group to ascertain their perceptions of the CHLS software. The total number of survey respondents was 73; 6 were excluded from the analysis due to damaged forms or incomplete answers. The internal consistency of the survey questions was relatively high ( 7 items; $\alpha=.85)$.

Table 5 shows students' responses regarding their interest in using CHLS to learn English. Using CHLS to learn English was "interesting" or "very interesting" to $35.82 \%$ of students. The $13.43 \%$ of students who reported it was "very interesting" may be the most suitable candidates for continuing selfstudy with CHLS. However, another $35.82 \%$ of respondents indicated that they found learning through CHLS "not interesting" or "not interesting at all."

Table 5

Interest in Learning through CHLS

\begin{tabular}{lccccc}
\hline $\begin{array}{l}\text { Level of } \\
\text { Learning } \\
\text { Interest }\end{array}$ & $\begin{array}{c}\text { Not } \\
\text { Interesting } \\
\text { At All }\end{array}$ & $\begin{array}{c}\text { Not } \\
\text { Interesting }\end{array}$ & Neutral & Interesting & $\begin{array}{c}\text { Very } \\
\text { Interesting }\end{array}$ \\
\hline$N(\%)$ & $7(10.45)$ & $17(25.37)$ & $19(28.36)$ & $15(22.39)$ & $9(13.43)$ \\
\hline
\end{tabular}

Participants were also asked their opinions about the difficulty of the CHLS content (see Table 6). Almost half (49.25\%) of the respondents thought the English content was slightly or very difficult. This response indicates nearly half of the students were not satisfied with the difficulty level of the content that they were asked to use for self-study.

Table 6

Difficulty level of CHLS

\begin{tabular}{lccccc}
\hline $\begin{array}{l}\text { Difficulty } \\
\text { Level }\end{array}$ & $\begin{array}{c}\text { Very } \\
\text { Difficult }\end{array}$ & $\begin{array}{c}\text { Slightly } \\
\text { Difficult }\end{array}$ & Neutral & $\begin{array}{c}\text { Slightly } \\
\text { Easy }\end{array}$ & $\begin{array}{c}\text { Very } \\
\text { Easy }\end{array}$ \\
\hline$N(\%)$ & $20(29.85)$ & $13(19.40)$ & $15(22.39)$ & $12(17.91)$ & $7(10.45)$ \\
\hline
\end{tabular}

When participants were asked to indicate the most significant advantage of CHLS English lessons from the options presented in Table 7, one quarter of the participants $(25.37 \%)$ appreciated easy access and the ability to repeat any content or task as many times as they wanted. This response acknowl- 
edges how CHLS's multimodal features support learners to engage more and enhance their understanding of the skills and concepts presented. Almost as many $(23.88 \%)$ identified the attractive visual content as satisfying. Participants also selected diverse contents (17.91\%), access to Q \& A boards (16.42\%), and audio features such as various pronunciation and accents $(10.45 \%)$ as advantages of the CHLS system.

Table 7

Advantages of CHLS English Content

\begin{tabular}{lc}
\hline Advantages of CHLS English Content & $N(\%)$ \\
\hline Animation and graphics (visual) & $16(23.88)$ \\
Various pronunciations and accents (audio) & $7(10.45)$ \\
Diverse contents (database) & $12(17.91)$ \\
Repeatability and easy access & $17(25.37)$ \\
Q \& A boards & $11(16.42)$ \\
Other & $4(5.97)$ \\
\hline
\end{tabular}

Subjects also mentioned a number of potential disadvantages of CHLS (see Table 8). For instance, $25.37 \%$ of participants reported that they had difficulty concentrating when they used CHLS to study English. Reasons cited for this lack of concentration included students' and parents' inability to understand cyber homework. Another disadvantage mentioned by $25.37 \%$ of participants was the lack of relationship of CHLS materials to their schoolwork. One final noteworthy result was that $19.40 \%$ of respondents indicated that the learning time with CHLS took longer than expected, but they would most likely work with CHLS.

Table 8

Disadvantages of CHLS English Content

\begin{tabular}{lc}
\hline Disadvantages of CHLS English Content & $N(\%)$ \\
\hline Difficult to concentrate on learning & $17(25.37)$ \\
Learning time is longer than expected & $13(19.40)$ \\
Not related to school lessons & $17(25.37)$ \\
Hard to understand & $11(16.42)$ \\
Difficult to make interaction (questions, answers, feedback) & $6(8.96)$ \\
Other & $3(4.48)$ \\
\hline
\end{tabular}


When asked "How many times would you use CHLS a week?", 73.13\% of the participants answered that they would use CHLS twice a week or more, while $26.87 \%$ responded that they would use it rarely or never (see Table 9). This result demonstrates that even with CHLS disadvantages, a larger proportion of students would use the system on a regular basis than not.

Table 9

Amount of CHLS Use

\begin{tabular}{lccccc}
\hline Continuous use & Never & Rarely & $\begin{array}{c}2-3 \text { times } \\
\text { a week }\end{array}$ & $\begin{array}{c}5 \text { times } \\
\text { a week }\end{array}$ & Daily \\
\hline$N(\%)$ & $8(11.94)$ & $10(14.93)$ & $18(26.87)$ & $20(29.85)$ & $11(16.42)$ \\
\hline
\end{tabular}

On both the open- and close-ended surveys, participants were asked if CHLS might possibly replace private tutoring. Over $50 \%$ reported that they would never or rarely replace private face-to-face tutoring with CHLS, while another $25 \%$ would only sometimes replace private tutoring with CHLS (see Table 10). Participants reasoned that CHLS interrupts their concentration because "using the computer leads me to play more online games" and "it takes too long to receive answers [from CHLS] for my question." Nearly 25\% reported that they could replace private tutoring with CHLS "usually" or on a "daily basis." They reasoned that "private tutoring is too expensive," "tutoring is stressful," and "[CHLS] helps me self-study."

Table 10

Possibility of using CHLS as a substitute for private tutoring

\begin{tabular}{lccccc}
\hline Possibilities & Never & Rarely & Sometimes & Usually & Daily \\
\hline$N(\%)$ & $19(28.36)$ & $15(22.39)$ & $17(25.37)$ & $9(13.43)$ & $7(10.45)$ \\
\hline
\end{tabular}

\section{Discussion}

In terms of the effect of the CHLS on students' English language learning, the results of the posttest suggest that practice with CHLS did not significantly improve participants' course performance. Some other reviews of extant research into CALL concur that there is limited evidence to show that technology has a direct beneficial impact on language performance (Kim \& Gilman, 2008; Macaro, Handley, \& Walter, 2012). However, these conclusions are contradicted by other studies that reported a significant difference in achievement in favor of CALL users over nonusers in learning English as a foreign language (Almekhlafi, 2006; Jung, 2002; Triantafillou et al., 2003).

The analysis of the posttest results of the lower, intermediate, and advanced groups suggests that CHLS English content was effective only to 
advanced students. A significant implication for pedagogy is that educators who work with online resources in their teaching should begin to offer students of all levels strategies for learning more complex and challenging materials and, even more importantly, strategies for learning online. In this way, students learn and build pedagogical strategies into their self-study in order to independently learn content and learn at their own pace.

It is interesting to note that the half of the subjects answered that they were interested in learning CHLS and thought the English content was difficult for them. This finding is of great importance to educators and parents, as it suggests that excessively challenging content could quickly lead to students' loss of interest and motivation. Therefore, CHLS designers must carefully consider the fundamental importance of content and tasks that are appropriate to learners' development levels. Subjects' survey answers about the advantages of CHLS English content were in accord with other commonly cited advantages of e-learning technologies such as ready access to information and educational materials through removal of time and location barriers (Kanuka, 2008). Other researchers support the finding that learners appreciate having more control over the content, pace, and media, which enables a greater personalized learning experience (Bernard et al., 2004; Chodorow, 1996; Littlejohn \& Pegler, 2014; Rosenberg, 2001; Wentling et al., 2000).

Participants noted that difficulty in concentrating on learning was a disadvantage of CHLS English content; this result is similar to Lee and Lee's (2005) finding that students were unsatisfied with their ability to concentrate on CHLS. Additionally, students in the digital age expect attractive and interesting features in Internet learning. Thus, creating English content that attracts and holds students' attention will very likely improve their concentration (Gee \& Hayes, 2011). Hwang et al. (2010) conducted research into the effectiveness of digital textbooks in schools and noted that "educational content still need[s] to be developed to satisfy the specific needs of teachers and subject matter. In addition, proper guidelines on how to adopt and implement educational content into classrooms should be provided" (p. 75). Further, Korean parents and students place extreme importance on strong standardized test performance. Based on these findings, CHLS designers should consider additional comparisons of CHLS and classroom content and tasks to identify potential discrepancies that may cause learners difficulties, and that may not provide them with the content they need to be successful on standardized tests. CHLS exists to supplement regular classroom instruction; however, when participants indicated that CHLS does not relate to schoolwork, this suggests to us that CHLS may not motivate students to continue their self-study.

As shown in the survey results, about $75 \%$ of the participants answered that they would use CHLS more than twice a week. As shown in the survey results (Table 9), about $75 \%$ of the participants answered that they would 
use CHLS more than twice a week. While Kwon et al. (2006) found that nearly $50 \%$ of the participants were satisfied with their learning through CHLS, our study implies, through students' interest, even greater satisfaction than Kwon's study, as 75\% indicated interest in spending two or more times weekly with CHLS. Adam and Nel (2009) found that participants had negative perceptions regarding online learning environments with no faceto-face interaction; our study also reports participants' dissatisfaction with some aspects of CHLS. However, participants also indicated that they would spend time weekly with the system's lessons. This suggests to us that CHLS may generate a "perceived positive effect" in learners. By this we mean that even though participants noted difficulties and challenges with CHLS, nearly $75 \%$ still reported that they would work at least weekly with the system. We suggest that participants perceive that time spent with CHLS may yield positive effects on their language learning and, ultimately, on standardized and course measures. Future research with the CHLS system might study how time working with CHLS content impacts achievement in the classroom and on standardized measures for language learning.

Despite the level of interest and advantages of CHLS, only $25 \%$ of subjects answered they would replace private face-to-face tutoring with CHLS. Yang (2003) points out that students tend to overcome their low motivation through private tutoring by building relationships with tutors, receiving supplementary lessons, and making up what was missed in the classroom. The classroom option of CHLS systems that have features of individual learning management might provide these advantages of tutoring to students, and e-learning systems may begin to replace traditional forms of private tutoring (Kwon et al., 2006).

This study provides some insight and direction in terms of how EFL learners perceive CHLS as an effective and helpful English-language learning tool, especially in perceived achievement and private tutoring. Even though participants in our study reported difficulties with content, lack of relationship to classroom learning, and challenges associated with CHLS, nearly $75 \%$ said they would "put in the time" weekly to work with the system. We suggest that because systems like CHLS identify specific learning outcomes for improving language learning, students perceive that if they go through the lessons they will become stronger language learners. This "perceived positive effect" may be the motivational drive to support students of all levels in the belief that they will achieve. Additionally, $50 \%$ of the students found that CHLS was valuable, which suggests that with further development based upon students' interests, engagement, and decision-making, there may be less need for private tutors. While reduction in private tutoring may not be an option for families who can-or who can make sacrifices to-afford it, there will be families who simply cannot afford private tutoring. We suggest that online systems of learning also take responsibility for student achievement and motivation, and build in pedagogical knowledge as well as content 
knowledge for students. That is, online systems could offer study strategies to support self-study students in understanding more complex or challenging content. This would encourage a more egalitarian approach to success and achievement in Korean education. All students and parents would have access to better tutoring through open-access systems meant to make educational resources equitable. The findings support research (Hwang et al., 2010; Kwon et al., 2006) that suggests that if parents wish to replace private tutoring with open-access online systems of learning, classroom instruction must consciously include strategies for online as well as face-to-face learning. In this way, students of all levels would be better positioned to learn through and with systems like CHLS. Such instructional support might dismantle the entrenched belief-especially in Korea - that private tutors will always support increased proficiency. A system like the CHLS may be a suitable alternative to private tutoring.

\section{Conclusion}

Previous research into online e-learning systems has revealed mixed results in terms of the effectiveness of online educational systems like CHLS to promote English language learning. Learners perceived that various e-learning systems for language learning afforded access to information, learner control, and a degree of authenticity. However, these systems also noted that challenges remain related to access to sufficient resources, suitable expertise to ensure efficient system use, and unresolved constraints on learner autonomy. The current study was designed to achieve several aims: (a) to determine the effect of the implementation of an online home learning system for supplementary practice on secondary students' English performance; (b) to understand which level of learner benefits from online learning systems like CHLS; and (c) to investigate students' opinions regarding their level of interest, the difficulty, and the advantages and disadvantages of the CHLS system.

In terms of the effect of the CHLS on students' learning of English, one intriguing finding was that although CHLS was not found to be more effective for the entire experimental group, when data were disaggregated by level the advanced learners in the experimental group did appear to benefit more than their counterparts in the control group. Thus, it appears that the effectiveness of this tool may depend on the ability level of the user. This may also support the finding in Table 6 in which participants discussed the challenging material, which may affect motivation for learning the English language. If content is too challenging, especially with self-study in which students are left to their own knowledge to learn, motivation may decrease, both in online resources and perhaps in classrooms that work with online resources. The second major finding from the survey research was that half of the students would continue to use CHLS, but not as a replacement for private tutoring. Students perceive 
CHLS as a supplementary learning tool rather than as a substitute for private tutoring. However, the remaining half of the participants suggested that they would replace private tutoring with CHLS sometimes, usually, or daily. Even though self-study in CHLS showed benefits for advanced learners in this study's results, we suggest that lower- and intermediate-level students certainly could benefit as well, especially if sustained classroom instruction engaged all learners in how to study lessons efficiently.

\section{Implications}

We argue that findings from the current study may address the challenges outlined at the start of this article: increased household private tutoring expenses, deteriorating quality of public education, and fierce competition for acceptance into top-tiered schools that suggest students will secure well-paying jobs upon graduation.

Although the CHLS system is designed to support all learners, this study found that it seemed to benefit only advanced learners of English in their self-study. However, we also found that over half of the students of all levels wanted to use CHLS to supplement their classroom learning. These findings suggest that, like face-to-face English language content taught in classroom spaces, educators must take time to instruct students not only on what they must learn but how to learn online, especially self-study. Thus this study argues for strong online strategy instruction in countries where open-access systems of learning language, like CHLS, are available.

This current study found that only advanced students benefited from CHLS self-study. The question must now become "How can CHLS benefit students who are at the beginning and middle levels of learning English?" Further development of programs like CHLS at these two levels would support these groups of students and make education delivered online stronger and more equitable. Lower- and middle-level students would see achievement and may therefore increase their own motivation to deepen their studies. Such study could then lead to a stronger educational system. An increase in student motivation may lead to better teacher self-image as both work toward a common goal: student success in school, which affords more opportunity for success in future studies and/or work.

However, for programs like CHLS to work, schools need parent commitment. Jang (2006) points out that the effect of replacing private tutoring was greatest among students with lower grades and in cases where parents participated in CHLS together with children. Parent participation appeared to be a very important factor in the effectiveness of CHLS, which confirms the necessity of more publicity and education to improve parents' understanding of CHLS. For parents, then, we see that studies that address home learning systems like CHLS may offer a reprieve from the financial constraints of individual tutoring. Further, with strong competition for spaces in highly reputable universities, parents can encourage their children to participate 
in programs like CHLS to supplement their in-school learning with out-ofschool and online learning to increase their chances of success.

Continued improvements in infrastructure and policies and familiarity and trust in online programs will facilitate the effective integration of programs like CHLS and encourage its widespread use in many countries. In particular, intensive efforts should be made to introduce online learning programs into regions that have historically had greater difficulty supporting learners through after-school programs or private tutoring. For example, rural communities, fishing settlements, and mountain villages would all seem to benefit greatly from access to online learning programs. Ultimately, ongoing refinement of programs like CHLS may reduce household private tutoring expenses and offer more equal access to English education in non-native English-speaking homes. Further, fierce competition, which fuels private tutoring, would open up opportunities for lower- and middle-level students, especially those in lower-income families. Online systems of learning like CHLS could support all students' intellectual curiosities and talents. For this aim to be realized, however, the system's quality should be continuously improved so that students have access to it and can feel confident that CHLS is more effective than the alternatives.

\section{Limitations of study}

Three limitations of the experiment design and implementation are noteworthy. First, the follow-up posttest coincided with the school midterm period. Consequently, it is possible that advanced-level students may have studied more intensively for the exam and that may be reflected in the experiment outcomes. Second, subjects in the experimental group had only one week of CHLS integration before beginning self-study in week two. If students had been offered more support across several weeks to learn the system, learn through the system, and learn with the system, those in the lower and intermediate levels may have seen more success and could have built their confidence in self-study. Third, a stronger random assignment to the experimental and control groups may be necessary to avoid "internal validity problems such as interaction between such factors as selection and maturation, selection and history, and selection and pretesting" (Dimitrov \& Rumrill, 2003, p. 160). However, randomization for the sake of randomizing may have its own limitations. Although this view of randomization is commonly accepted, researchers must be open to other ways to randomize groups. The teacher in this study took into consideration several criteria, including test scores and grade point averages. This provides a randomization that is relevant and authentic to classrooms in schools. Other variables - such as students' ability to work in small and/or large groups, if they are silent/more vocal, if they are more/less self-directed-might be taken into consideration in the results to allow for deeper understandings of how language learning occurs. 


\section{Further questions for investigation}

This research has illuminated a number of questions in need of further investigation. First, further work needs to be done to establish whether there is a relationship between student interest in online learning tools or the motivation to use them and their ability to benefit from using them. Second, it may be beneficial to examine whether more fine-tuned learner needs analysis, that ensures a closer alignment between content and student ability level, impacts their interest level and performance. Researchers also need to clarify whether it is the level of the student or the suitability of the materials that allowed some ability groups to improve and others not. To improve the effectiveness of programs like CHLS and distribute positive educational impact, English content may need to be adjusted to better suit learners' developmental and task-performance abilities. By diversifying supplementary and intensive learning content and balancing the difficulty levels, students may better maintain their interest in learning with programs like CHLS. Lastly, future research might explore in greater depth learner perceptions of the advantages and disadvantages of the CHLS system. This could be accomplished with qualitative interviews that enable the researcher to ask more probing follow-up questions. These findings may help researchers and designers refine their understandings of the strengths and limitations of the system.

\section{The Authors}

Ji Hye Shin is a doctoral student in the Department of Middle and Secondary Education at Georgia State University, Atlanta, GA, USA. Her research interests include EFL learners, second and foreign language pedagogy, web-assisted language learning, e-learning, dialogue in middle and secondary students, and teacher education.

Dr. Peggy Albers is a professor in the College of Education and Human Development at Georgia State University. She teaches literacy courses at the graduate level, and works with preservice and inservice teacher preparation in the field of literacy education. Her current interests are semiotics, children's literature, integration of multimedia into curriculum, and doctoral preparation.

\section{References}

Adam, S., \& Nel, D. (2009). Blended and online learning: Student perceptions and performance. Interactive Technology and Smart Education, 6(3), 140-155.

Almekhlafi, A. G. (2006). The effect of computer assisted language learning (CALL) on United Arab Emirates English as a Foreign Language (EFL) school students' achievement and attitude. Journal of Interactive Learning Research, 17(2), 121-142.

Barbour, M. K. (2012). State of the nation: K-12 online learning in Canada. Retrieved from http:// www.openschool.bc.ca/pdfs/iNACOL_CanadaStudy_2012.pdf

Barbour, M. K., \& Stewart, R. (2008). A snapshot state of the nation study: K-12 online learning in Canada. Vienna, VA: North American Council for Online Learning. Retrieved from http:// www.inacol.org/wp-content/uploads/2015/02/NACOL_CanadaStudy_2008.pdf

Bernard, R. M., Abrami, P. C., Lou, Y., Borokhovski, E., Wade, A., Wozney, L., ... Huang, B. (2004). How does distance education compare with classroom instruction? A meta-analysis of the empirical literature. Review of Educational Research, 74(3), 379-439. 
Beetham, H., \& Sharpe, R. (2013). Rethinking pedagogy for a digital age: Designing for 21st century learning (2nd ed.). New York, NY: Routledge.

Bouhnik, D., \& Marcus, T. (2006). Interaction in distance-learning courses. Journal of the American Society for Information Science and Technology, 57(3), 299-305.

Chapelle, C. A. (2005). Interactionist SLA theory in CALL research. In J. Egbert \& G. Petrie (Eds.), Research perspectives on CALL (pp. 53-64). Mahwah, NJ: Lawrence Erlbaum.

Cho, Y.-S., Kim, J.-W., Bae, W.-I., \& Choi, S.-K. (2009). The national innovation model: Korea's cyber home learning system. Korea Education \& Research Information Service (KERIS). Retrieved from http://english.keris.or.kr/ICSFiles/afieldfile/2009/01/09/CHLSofKorea.pdf

Chodorow, S. (1996). Educators must take the electronic revolution seriously. Academic Medicine, 71(3), 221-226.

Dimitrov, D. M., \& Rumrill, P. D. (2003). Pretest-posttest designs and measurement of change. Work, 20(2), 159-165.

Gee, J. P., \& Hayes, E. R. (2011). Language and learning in the digital age. New York, NY: Routledge.

Heift, T., \& Chapelle, C. A. (2012). Language learning through technology. In S. M. Gass \& A. Mackey (Eds.), The Routledge handbook of second language acquisition (pp. 555-569). London, UK: Routledge.

Herrington, J., Reeves, T. C., \& Oliver, R. (2010). A guide to authentic e-learning. New York, NY: Routledge.

Hwang, D. J., Yang, H.-K., \& Kim, H. (2010). E-learning in the Republic of Korea. UNESCO Institute for Information Technologies in Education. Retrieved from http://iite.unesco.org/pics/publications/en/files/3214677.pdf

Jang, S.-H. (2006). Analysis on the effectiveness of Cyber Home Learning System. Korea Education and Research Information Service. Retrieved from http://english.keris.or.kr/ICSFiles/afieldfile/2006/08/10/KERISRandD.pdf

Jung, S. (2005). E-learning quality management guideline for national e-learning quality management center operation. Seoul, Korea: Korea Education and Research Information Service.

Kanuka, H. (2008). Understanding e-learning technologies-in-practice through philosophies-inpractice. In T. Anderson (Ed.), The theory and practice of online learning (2nd ed., pp. 91-118). Edmonton, AB: Athabasca University Press.

Kim, D., \& Gilman, D. A. (2008). Effects of text, audio, and graphic aids in multimedia instruction for vocabulary learning. Educational Technology \& Society, 11(3), 114-126.

Kwon, S., Lim, S., Lim, J., Lee, J., Park, S., Shin, S., ... Jang, S. (2006). An evaluation study of effectiveness of the Cyber Home Learning System for primary and secondary school students. Seoul, Korea: Korea Education and Research Information Service.

Lee, J., \& Lee, C.-H. (2005). Teachers' perception of cyber home work for primary and secondary school students. Multimedia-Assisted Language Learning, 8(2), 154-178.

Lee, Y.-J., \& Koo, H. (2006). "Wild geese fathers" and a globalised family strategy for education in Korea. International Development Planning Review, 28(4), 533-553.

Littlejohn, A., \& Pegler, C. (2014). Preparing for blended e-learning. New York, NY: Routledge.

Macaro, E., Handley, Z., \& Walter, C. (2012). A systematic review of CALL in English as a second language: Focus on primary and secondary education. Language Teaching, 45(1), 1-43.

McAuley, A., Stewart, B., Siemens, G., \& Cormier, D. (2010). The MOOC model for digital practice. Retrieved from http://www.elearnspace.org/Articles/MOOC_Final.pdf

Ministry of Education, Science and Technology (MEST) \& Korea Education and Research Information Service (KERIS). (2012). Adapting education to the information age. Seoul, Korea: Author.

Murphy, E., Rodríguez-Manzanares, M. A., \& Barbour, M. (2011). Asynchronous and synchronous online teaching: Perspectives of Canadian high school distance education teachers. British Journal of Educational Technology, 42(4), 583-591.

Park, J. K. (2009). "English fever" in South Korea: Its history and symptoms. English Today, 25(1), $50-57$. 
Rosenberg, M. J. (2001). E-learning: Strategies for delivering knowledge in the digital age. New York, NY: McGraw-Hill.

Sitzmann, T., Kraiger, K., Stewart, D., \& Wisher, R. (2006). The comparative effectiveness of webbased and classroom instruction: A meta-analysis. Personnel Psychology, 59(3), 623-664.

Su, B., Bonk, C. J., Magjuka, R. J., Liu, X., \& Lee, S.-H. (2005). The importance of interaction in web-based education: A program-level case study of online MBA courses. Journal of Interactive Online Learning, 4(1), 1-19.

Triantafillou, E., Pomportsis, A., \& Demetriadis, S. (2003). The design and the formative evaluation of an adaptive educational system based on cognitive styles. Computers \& Education, 41(1), 87-103.

Verduin, J. R., \& Clark, T. A. (1991). Distance education: The foundations of effective practice. San Francisco, CA: Jossey-Bass.

Wentling, T. L., Waight, C., Gallaher, J., La Fleur, J., Wang, C., \& Kanfer, A. (2000). E-learning: A review of literature. Urbana-Champaign, IL: University of Illinois Press.

Woo, Y., \& Reeves, T. C. (2007). Meaningful interaction in web-based learning: A social constructivist interpretation. Internet and Higher Education, 10(1), 15-25.

Yang, J. H. (2003). Analysis on the motivation of middle school students to participate in private tutoring. Korea Education Journal, 30(2), 261-283.

Zhang, D. (2005). Interactive multimedia-based e-learning: A study of effectiveness. American Journal of Distance Education, 19(3), 149-162. 